\title{
The role of the media in staging air pollution: the controversy on extreme air pollution along Oxford Street and other debates on poor air quality in London
}

\author{
Anneleen Kenis ${ }^{\mathrm{a}^{*}}$ and Benjamin Barratt ${ }^{\mathrm{b}}$ \\ ${ }^{a}$ Research Foundation Flanders (FWO), Division of Geography and Tourism, KU Leuven, Belgium \& \\ Department of Geography, King's College London, UK, Email: anneleen.kenis@kuleuven.be \\ ${ }^{b}$ Environmental Research Group, School of Public Health, Imperial College London, UK, Email: \\ b.barratt@imperial.ac.uk
}

This is the accepted version of an article which is published in Environment and Planning C: Politics and Space. Please check the following website for the final, published version: https://doi.org/10.1177/2399654420981607

To cite this article: Kenis A. and Barrett, B. (2021). The role of the media in staging air pollution: The controversy on extreme air pollution along Oxford Street and other debates on poor air quality in London. Environment and Planning C: Politics and Space. doi:10.1177/2399654420981607

Anneleen Kenis is a Senior Research Fellow of the Research Foundation Flanders (FWO), affiliated with the Division of Geography and Tourism at KU Leuven and the Centre for Sustainable Development at Ghent University (Belgium). Her work is situated in the broad field of political ecology, focussing on processes of politicisation and depoliticisation in relation to climate change, air pollution and genetic engineering. The work for this paper was conducted while being affiliated with respectively the Environmental Research Group and the Department of Geography at King's College London (UK).

Benjamin Barratt is a Reader at Imperial College London. His early research evaluated the impact of policy interventions on London's air quality, including the London Congestion Charging Scheme and Low Emission Zone. The focus of his current work is to better characterise individual and populationlevel exposure to environmental stress, how this relates to the health of susceptible population subgroups, and methods of public health improvement.

*Corresponding author. Email: anneleen.kenis@kuleuven.be. Postal address: Anneleen Kenis, Division of Geography and Tourism, Celestijnenlaan 200E, 3001 Heverlee, Belgium. 


\title{
The role of the media in staging air pollution: the controversy on extreme air pollution along Oxford Street and other debates on poor air quality in London
}

\begin{abstract}
Mapping the media frames that have both triggered and articulated the mobilisation around air pollution in London in the period 1997-2017, this paper shows how especially those events that have been framed in agonistic terms have led to a rise of media engagement with the topic. From the controversy around Sahara dust as a so-called 'natural' explanation for smog episodes, to the staging of Oxford Street as the most polluted street of the world, from Sadiq Khan's decision to join ClientEarth in its court case against the UK government to the debate on a new runway for Heathrow, from the Volkswagen scandal to the Black Lives Matter blockade of London City Airport: the discursive construction of us/them divides has been crucial in sparking passion, contestation and debate. Empirically, the paper starts from a detailed study of 1594 newspaper articles that appeared on air pollution in five British newspapers, The Guardian, Financial Times, The Independent, The Daily Telegraph and The Times, between January 1997 and March 2017. Theoretically, it combines Chantal Mouffe's political theory with Anabela Carvalho's media theory, in particular her diachronic model of circuits of culture. On this basis, the paper distinguishes five critical discourse periods and shows how a number of critical discourse moments, exactly because of their agonising dimension, have been able to spike media attention and shift the terms of the debate. Starting from this observation, the paper argues that media processes should not only be understood in cyclic terms, but can also trigger non-linear iterative dynamics, leading to upward spirals characterised by thresholds and a gradually increasing level of interest overall, in this case raising the profile of London's poor air.
\end{abstract}

\section{Introduction}

'Air pollution has had a much higher profile in the last two or three years than [...] in my whole career. Now, air pollution is big news, especially in London' Atmospheric scientist, London, Spring $2017^{1}$

Air pollution has been successfully staged as a matter of public concern in London (UK) in the period 2014-2017. How did this shift in public awareness and engagement take place? While studies have looked at the role of perceptions (Bickerstaff and Walker, 2001; Day, 2007), community action and involvement (Wakefield et al., 2001), unjust distributions (Mitchell and Dorling, 2003; Pearce et al., 2011), gender differences (Cupples et al., 2007) and cultural, affective and artistic dimensions (Adey, 2013; Cupples, 2009; Engelmann, 2015), in the discursive construction of air as a matter of public concern, studies that analyse the role of the media are largely missing. 2 This is surprising as media 'are considered important agents in the production, reproduction and transformation of the meanings of social issues', as Carvalho (2010: 172) notes. Together with a number of other scholars, Carvalho (2008, 2010) illustrates how social actors' perceptions, opinions and actions are to a large extent shaped by mediated information and interpretation (Mayer, 2012; Seale, 2003).

To address this gap, this paper presents a study on the role of the media in putting air pollution on the public agenda in London. It draws on an extensive analysis of more than 1500 media articles covering the period 1997 to 2017. The analysis aims at mapping the emergence and articulation of those discursive frames that have triggered the wider uptake of and mobilisation around air pollution as a

\footnotetext{
${ }^{1}$ Abstract of an interview conducted with an atmospheric scientist in London in Spring 2017.
} 
matter of concern. Our argument will be that it is a particular, agonistic kind of discursive framing of events, based on the discursive construction of an us/them divide, that has been key to making air pollution into a topic of public awareness and debate.

While other scholars have analysed how media discourses can work in an either politicising or depoliticising way, and can thus contribute to creating or closing down spaces for democratic debate (Craig, 2010; Maeseele, 2015; Maeseele and Raeijmaekers, 2017; Olausson, 2010; Pepermans, 2015), this paper makes a theoretically related yet different point. Starting from the work of Mouffe (2006, 2002), the focus is on how conflict can be a key mobiliser of political passions and can thus generate a spiral of increased media interest, citizen engagement and political action. In other words, whereas the focus of previous research on media and the political has been on the analysis of the (de)politicising effects of particular discursive framings as they can be found in media outlets, the current article focusses on the 'media ecosystem', and argues that the conflict which emerges from the interplay of different media interventions can stir public passion, contestation and debate, even though the framings presented in particular media outlets might be depoliticising in themselves. As we will show in what follows, especially those events that triggered conflict led to a rise of media engagement with the topic.

This media engagement cannot be seen in isolation from how broader layers of society took the issue up and started engaging with it. While the increase of public engagement with air pollution is not the focus of this research article, it is relevant to note that the exponential increase in media coverage from 2014 onwards was paralleled by an upsurge of citizen initiatives, a redirection of environmental and health campaigns towards air pollution and a more prominent engagement with the issue in policy circles (Kenis, 2020; Kenis and Lievens, 2021). In this sense, the relation between media attention and public engagement appears as a cyclic iterative process leading to an upward spiral of interest in the topic from 2014 onwards. To understand this dynamic, it is important to see that media not only shapes, but also expresses public opinion (Carvalho, 2008, 2010). Spikes in media coverage therefore not only exemplify but might also trigger public engagement and debate.

In the next section, we will first elaborate on the discursive processes which take place in constructing air pollution as a matter of public concern and present a political reading of Carvalho's critical discourse approach to media processes, drawing on Mouffe's $(2002,2006)$ work in political theory. Subsequently, we will outline the rationale for our methodological approach, after which we present the five critical discourse periods we have been able to distinguish on the basis of our analysis. Finally, we discuss the driving forces behind the growth of media attention on the topic, and show how similar processes can also lead public interest to wither away again.

\section{The media and the political}

Media coverage of air pollution requires a process of translation: a largely invisible issue has to be made salient through discourse. This process of translation is a process of discourse construction whereby particular elements are included and excluded, relations between them established and patterns of meaning emerge (Kenis, 2020; see also Howarth, 2000; Howarth et al., 2000; Laclau and Mouffe, 2001). While this process of construction arguably takes place for every event covered by media, the invisibility of many environmental issues makes the decisions and choices involved even more significant. Therefore, it should not come as a surprise that many media studies on environmental issues focus on the extent to which the media give a 'truthful' representation of the 
scientific debate (Antilla, 2005; Boykoff, 2008; Dispensa and Brulle, 2003; Moyer et al., 1995). The focus of media analysis is then on problems of inaccuracy, bias and sensationalism in reporting, leading to pleas for a more detailed discussion of the scientific characteristics (uncertainty, statistics, timescales, etc). However interesting, this focus is based on a simplification of how media work (Pepermans and Maeseele, 2014). Moreover, it neglects that consuming knowledge is not a passive process and that consumers can become active producers of knowledge in their turn (Carvalho and Burgess, 2005). In other words, it neglects the social life of a media outlet: the relations and processes of production that brought it into being, as well as the processes and relations that it creates itself. But most importantly, it neglects that ultimately it is impossible for media discourses to be an exact or accurate translation of a scientific 'fact'. There is no final, prediscursive point to rely on. The result of discourse construction is never a mere 'framing' of an environmental issue that is itself not yet discursive. As Latour (2004) famously argues, a matter of fact is always already a matter of concern. In order to give a more comprehensive account of media processes and their effects, this paper elaborates on Carvalho and Burgess's (2005) 'diachronic model of circuits of culture', which we look at specifically from the perspective of theories of 'the political', more specifically the work of Chantal Mouffe $(2002,2006)$. It is our contention that combining Carvalho's $(2005,2008,2010)$ work on the media with Mouffe's political-theoretical insights can shed a new light on how processes of politicisation can occur through the dynamics of the media ecosystem. Following Mouffe, 'the political' should be distinguished from the more conventional notion of 'politics', which deals with institutions like the parliament and voting. In contrast, 'the political' refers to the inescapable dimension of power, conflict, decision, choice, contingency, exclusion and plurality in social relations. Importantly, it is on the level of discourse that the political or (de)politicisation have to be understood and assessed (see also Kenis, 2015, 2019a; Kenis and Lievens, 2014). The social is discursively constructed, and the question is therefore to what extent discourse understands or recognises itself as political. Discourse has a larger meaning here than in studies which merely consider it as a set of ideas or beliefs shared by a group of people (Howarth et al., 2000). Discourses are products of political hegemonies and inevitably produce exclusions on the basis of which antagonisms can arise. That is why the construction of the social through discourse has a constitutively political dimension, and why power is at the heart of the social: there is no social relation which is not the product of power. It is in this sense that Laclau and Mouffe affirm 'the primacy of politics in their social ontology' (Howarth, 2000: 104, see also Howarth et al., 2000). According to Mouffe's later work $(2002,2006)$, the political is about recognising the constitutive reality of antagonism. Whereas this political dimension is constitutive for the social, it can be discursively recognised and affirmed, but it can also be concealed or ignored. That is why producing discourse is never innocent or neutral. It is a highly political process, even though its political nature can remain implicit or unacknowledged. For this reason, the revelation of the antagonistic dimension of a social issue is crucial to politicise it.

Carvalho and Burgess's (2005) 'diachronic model of circuits of culture' starts from a slightly different, though conceptually related theoretical framework, namely Critical Discourse Analysis (CDA), as principally developed by Fairclough (1995), van Dijk (1988) and Wodak (1999).3 Maeseele (2015) and Pepermans $(2015)$ argue that Carvalho's $(2007,2008,2010)$ analytical framework is most suitable for analysing processes of politicisation and depoliticisation in media discourses as it explicitly looks at 'the implications of ideology for the selection, interpretation, and presentation of key news elements in media outlets' (Pepermans, 2015: 23) and 'the symbolic environment in enabling political (dis)engagement' (Pepermans, 2015: 10). However, Pepermans and Maeseele concentrate on the 
(de)politicising qualities of individual newspaper articles, focussing less on how different media outlets interact with each other and thereby can create broader dynamics of (de)politicisation.

In order to understand what is exactly at play, it is crucial to elaborate on the three moments which Carvalho and Burgess's (2005) distinguish in the life cycle of media discourses. The first moment, the moment of production, refers in their model to the fabrication of stories by media professionals starting from source materials. This is, as also Maeseele (2015) and Pepermans (2015) show, already a highly political process in which particular events are included and others are excluded. Furthermore, as Carvalho and Burgess argue, the way in which an event is discursively constructed as 'newsworthy' is deeply influenced by socially constructed ideas on what is interesting, the available framings and predominant ideas on how stories should be told. As several scholars show, largely invisible issues such as air pollution, with all their uncertainties, statistics, correlations and timescales pose specific challenges in this context (Carvalho, 2007; Mayer, 2012; Seale, 2003). The second moment, that of public dissemination, refers to the visual and other techniques which aim to persuade people to take a look at the news item, make them interpret it in a particular way and convince them of the truthfulness of the message. Here again, discursive choices will reinforce particular framings and silence others. The third moment, the moment of consumption, Carvalho and Burgess underscore, should not be considered a passive process. People have the capacity to resist or subvert discursive interpretations put forward by the media. Here again, largely invisible issues like air pollution bring specific challenges. How to open up a space for critically engaging with scientific analyses without ending up in scepticism (see also Davies and Mah, 2000)? Confronting audiences with scientific uncertainty, the contestation of science or the presence of contradictory scientific claims does not automatically lead to a more nuanced and complex understanding of science, but can also lead to a simplification of the debate in terms of believers and disbelievers (Pepermans and Maeseele, 2014). Importantly, in Carvalho and Burgess' model, the third moment feeds back into the first, as 'media consumers' can become 'media producers' in their turn by writing reader letters and opinion pieces, sharing texts on social media, liking them, or just clicking on them. This will make topics rise in the statistics and encourage journalists to write more about them. More broadly, people influence the media by engaging in neighbourhood committees and action groups, attending public events, signing petitions or voting for politicians who embrace certain demands. These events can become news stories in their turn, and thereby further reinforce interest and debate.

This feedback loop will figure centrally in our analysis. As we will show, it reached an (at least temporary) peak in London in February 2017 when a cyclic iterative process of media and public interest led to an exceptional amount of media coverage of air pollution. Our analysis will focus on the processes which brought this cyclic iterative process into being and kept it going. In order to do that, we will rely on a Mouffian reading, showing how the discourses involved where characterised by an agonistic dynamic.

\section{Methodology}

The study covers the media debate on air pollution in London (UK) in The Guardian, Financial Times, The Independent, The Daily Telegraph and The Times from January 1997 until March 2017 The media analysis was part of a broader project which also included 30 in-depth interviews with air pollution campaigners, policy makers, business representatives and activists in Spring 2017 as well as focus groups with citizens, and participant observation in numerous activities, lectures and debates. While 
not being the main focus of this article, this broader engagement with the topic provided us with important keys to interpret the media coverage. As Baxter and Eyles (1997) argue, data triangulation is a crucial tool to enhance credibility. In the selection of newspapers we followed Carvalho and Burgess' (2005) recommendation to focus on 'leading' newspapers which are characterised by indepth and high-quality media coverage and which tend to set the terms of the debate, also towards other newspapers. Without much doubt, the choice for these particular newspapers had a significant effect on the analysis made. Focussing on newspapers with a more populist orientation, for instance, might have given more insight into the way the topic has been popularised to a broader public. Being the first analysis of its kind, however, it is our contention that we first needed to gain more insight into how the general terms of the debate are set. Starting from these premises, 1594 articles were selected in which air pollution or air quality is (one of) the main topic(s) of the narrative. The articles were collected through an automatic search via the NEXIS@ database (keywords: 'air pollution' OR 'air quality' 'at the start' in the 'United Kingdom', 'exclude newswires' and 'group duplicates') after which we conducted a manual check. This check allowed us to exclude duplicates, highly similar articles which are mostly updated versions of articles which were published earlier -, and articles which did not deal with air pollution/quality as their main focus of interest. As the study focused on London, articles were excluded which dealt with air pollution in other localities.

Subsequently we produced time series charts of article frequency which allowed us to visualise time trends. The charts display the number of articles which appeared on the topic in each month between January 1997 and March 2017. On this basis a preliminary identification of critical discourse moments and periods was made (see also Carvalho, 2008; Pepermans, 2015; Pepermans and Maeseele, 2014; Carvalho, 2007). A critical discourse moment refers to a moment of high media coverage which often produces a fundamental shift in the terms of the debate. A critical discourse period is defined as a longer period of time during which media coverage displays a set of more or less constant or similar characteristics. It can include the period building up to a critical discourse moment or can bring several critical discourse moments together if they share significant and substantial features. Subsequently, we engaged in a qualitative analysis to understand what precisely happened during each of these periods and moments. Thereby, the focus was not so much on the textual level and the discursive details of individual newspaper articles, but on the contextual level (Maeseele, 2015) with a focus on the historical-diachronic axis, or, in other words, the temporal sequences, evolutions and the broader context in which particular evolutions take place (Pepermans, 2015). Practically, this meant reading through all articles several times and coding key nodal points (Howarth et al., 2000). Because the articles were drawn from the NEXISC database, we did not have the possibility to look at morphological characteristics like structural organisation and layout. This qualitative analysis not only gave us insight into the key elements structuring the debate, it also motivated us to reconsider some of the earlier defined critical discourse periods and moments. For instance, we realised that the peak in media coverage in April 2015 did not initiate a new critical discursive period but rather confirmed and ended the previous one. Similarly, it became obvious that a new period started in July 2015 even though the peak in media coverage was less high on that moment than it was in April of that year. ${ }^{2}$

\footnotetext{
${ }^{2}$ Importantly, what appears as a peak in a graph is always dependent on the analytic choices made. If media attention for the Volkswagen scandal would have peaked earlier in the month - and thus would not have been spread out over two months - we would probably have observed a much higher peak.
} 
Finally, we looked at recurrent trends or elements which could explain the general course of the debate.

\section{A discursive political-theoretical media analysis of the air pollution debate in London}

The analysis of the time series charts enabled us to observe two significant patterns: (1) a cyclic movement of spikes of interest and calmer periods and ('2), a gradually increasing general level of interest in air pollution as represented in media coverage (see figure 1 and figure 2). Taking these two observations together, we observe an upward spiral: after peaking, the interest stays higher than before and does not fall back to its previous levels again. In order to understand the processes behind this dynamic, we need a qualitative analysis. In what follows we present the outcomes of this exercise, focussing on those critical discursive moments and periods which have been crucial in redefining and reshaping the terms of the debate. We realise that this also leaves out or even conceals a number of debates which might have been intrinsically important but did not lead to a peak in media coverage. We will discuss the first critical discourse periods in detail in order to illustrate how the general dynamic typically unfolded. For the subsequent critical discourse periods we will only point to the general conflict lines. The underlying dynamics are the same.

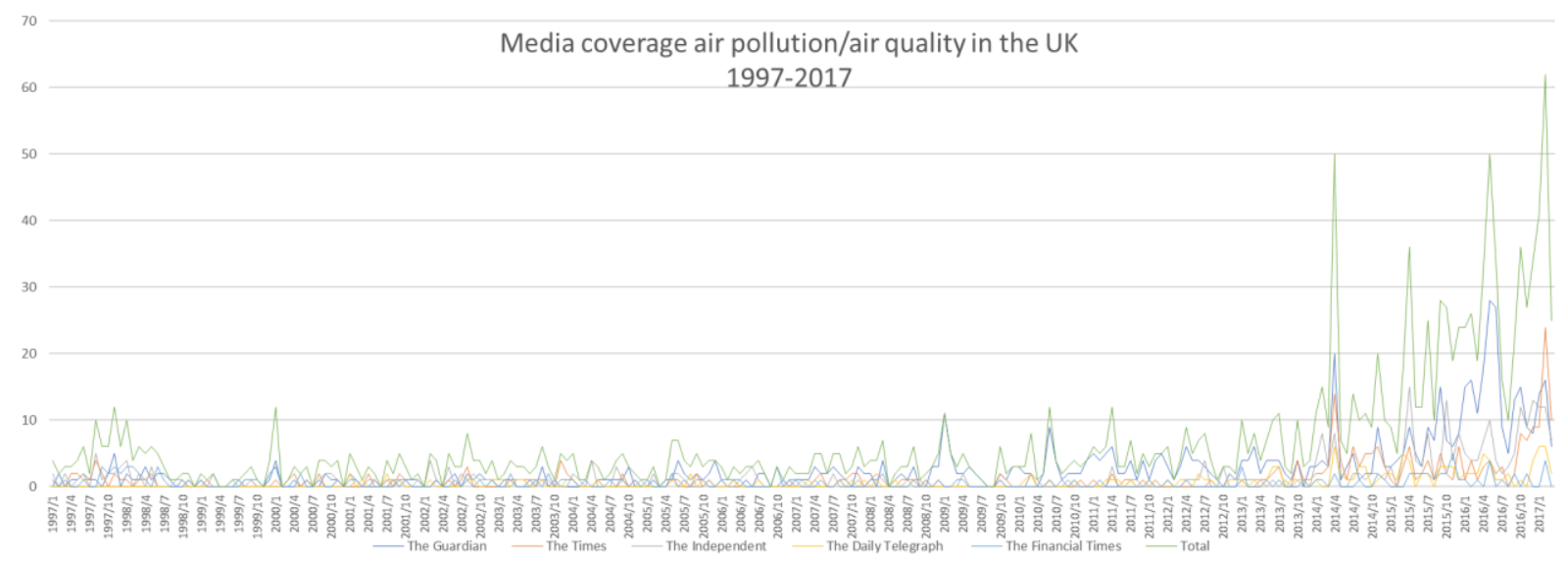

Fig. 1. Number of articles published on air pollution/air quality in the UK per calendar month (January 1997-March 2017) 


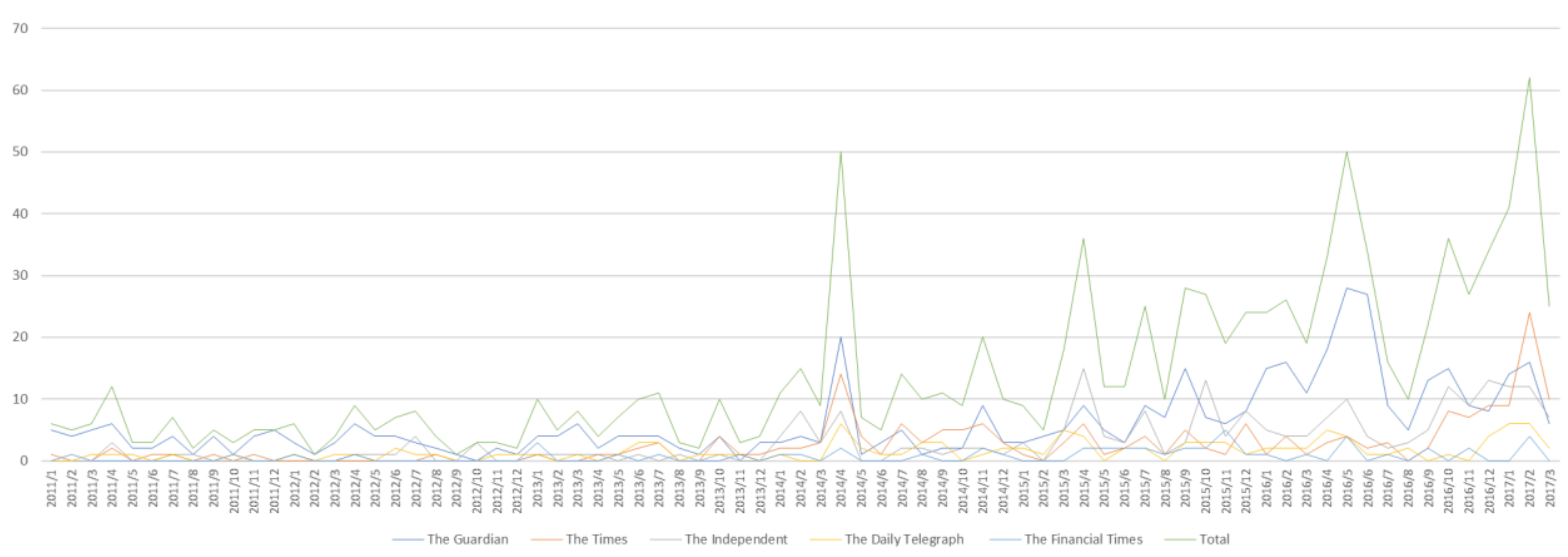

Fig. 2. Number of articles published on air pollution/air quality in the UK per calendar month (January 2011 - March 2017)

\subsection{Critical discourse period of January 1997 - March 2014: key elements are present, but the interest does not catalyse}

The period of 1997 until March 2014 was characterised by a long period of generally low interest in air pollution. Newspaper articles on the topic were written, bringing about a range of different angles and perspectives, but there was no more substantial engagement with the topic. Most articles were 'singular' articles without any connections between them. They did not lead to further discussions, replies, or more in-depth engagements with the topic. They seemed to be mainly press-release based, or the result of the personal interest of a single journalist.

At the same time, several of the topics which would later become issues of huge contestation were already present in the media during this period: detrimental health effects, failure to comply with European legislation, smog episodes, Heathrow, diesel, the Congestion Charge and Bonfire night. At this stage, however, they failed to trigger a larger debate, even though efforts were made to stage the issue along these lines. 'Traffic fumes "kill more than crashes"' (The Independent, 13 October 2000), 'Tube air "a danger to very young and elderly"' (The Independent, 9 July 2001), 'Asthma risk greater if children play outside' (The Daily Telegraph, 1 February 2002), 'The government must act now on air pollution' (The Independent, 17 February 2002), 'Breathing polluted city air may be worse for you than fallout from an atom bomb' (The Times, 3 April 2007): all these articles cannot, in themselves, be distinguished from articles published more than a decade later when interest in air pollution really peaked. In other words, it is not the discursive staging of the topic through singular articles that mattered. Something else was needed to generate a broader dynamic.

Despite the lack of a real acceleration of the debate, there were some small spikes in media coverage. Some of them did not embody more than the simultaneous occurrence of several newsworthy items, but a few demonstrated a more significant dynamic. The most important of these small spikes related to smog episodes (e.g. January 2000), the discussion on Heathrow extension (e.g. January 2009), EU warnings (e.g. June 2010), the accusation that London's Mayor, Boris Johnson, delayed or downplayed air pollution reports and policies (June 2010), his attempt to techno-fix the problem by 'glueing' air pollution to the road (April 2012 and March 2013), the Olympic Games (April - August 2012) and finally 
the communication of new scientific findings, including the new figures of 35,000-50,000 premature deaths/year (March 2010) and air pollution effects on cancer and low birth weight (October 2013). While all these topics led to small spikes in public interest, none of them succeeded in really catalysing interest and debate. However, that does not mean that they have not been important. They might have been crucial in preparing for the media storm that would come afterwards. Subtly, three story lines started to unfold; (i) the indignation resulting from Boris Johnson's lack of serious engagement with the issue, (ii) the discussion on Heathrow and the conflict line opposing economy to ecology and (iii) the ongoing lack of compliance with EU legislation. All three would turn out to be crucial in later debates.

\subsection{Critical discourse period of April 2014 - June 2015: Sahara dust and Oxford Street}

From April 2014 onwards we can delimit a new critical discourse period. Not only do we observe an unprecedented peak in media coverage in April 2014, the interest is also maintained from then onwards. In other words, we observe the start of an upwardly spiralling cyclic iterative process which, as we will argue, leads in a self-reinforcing way to increasing media and public debate. But what created this first critical discourse moment in April 2014?

To start with, a building up of interest and debate can be observed in the period January - February 2014. Most importantly, on the $20^{\text {th }}$ of February, the European Commission launched legal action against the UK for failing to reduce 'excessive' levels of air pollution. The threat of a GBP 300 million fine as a result of ' 15 years of warnings and several extensions and postponements granted to the government' (The Guardian, 20 February 2014), was broadly covered in the media. Then, on the $31^{\text {st }}$ of March, a major smog alert was issued and broadcast by the Met Office on the national television for the very first time. This came together with an unusual visibility of the problem: even prime minister David Cameron's car was covered by 'Sahara dust', so reported the media.

However, these events in themselves cannot fully explain the media storm and related peak in public interest and awareness. Similar situations had occurred before. The argument we want to put forward in this paper is that the crucial factor was the emergence of a conflictual dynamic. Air pollution was discursively taken up by key actors, but at the same time dismissed as not 'serious' and framed as a 'natural' phenomenon we cannot do much about. David Cameron publicly declared that the smog was not more than 'a naturally occurring weather phenomenon' and Boris Johnson infamously stated: 'I' $m$ urging people just to have a little balance here. I cycled this morning and it seemed perfectly fine to me. I think we need to keep a little bit of a sense of proportion' (The Times, 4 April 2014).

Our argument is that it was this dismissal of the seriousness and nature of the crisis (soon afterwards it turned out Sahara dust was not the main culprit) that triggered a lot of reaction, even outrage, and media debate. To fully understand what is at play, Mouffe's $(2002,2006)$ work on political subjectivity is a useful starting point. The discursive framing of an issue as divisive and the visible representation of different 'camps' which take opposite views on the issue produce a double effect. On the one hand, the opposition between different viewpoints makes the stakes of the issue visible, and this enables citizens to better understand what is politically at play. The mediatised confrontation between different viewpoints makes the stakes more easily interpretable than when the issue is portrayed in a neutral, technocratic way. On the other hand, as a result of this visibility the conflict stirs the passions of the public, and shows that something important is at stake. As Mouffe $(2002,2006)$ argues, it is only when division is visibly portrayed that people are challenged to find and elaborate their own position. 
This is the reason why representing society as divided can result in a growing political awareness and the creation of novel spaces of democratic debate and participation. The observation that the conflict on 'Sahara dust', as played out in the media, triggered interest, passion and awareness far beyond the media exemplifies this point. In our study this was, for instance, evidenced in the number of Google searches on air pollution (see Figure 3 ) but also in the subjective experience of our interviewees. While we conducted the interviews almost three years later, almost all respondents stated that they clearly remembered the Sahara dust story and that they had perceived an increase in citizen awareness and public engagement on the topic since then.

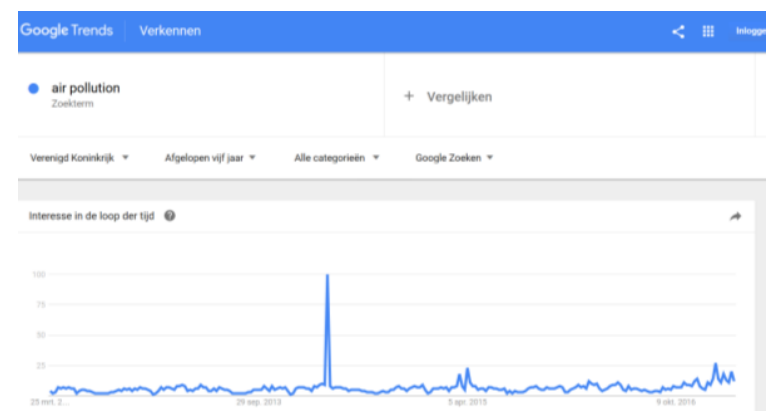

Fig 3. Number of people who searched 'air pollution' on Google 2012 to 2017.

Summarised, we observe the emergence of different fault lines, centred around diverging nodal points, around which discursive competition unfolds. In the period from April 2014 onwards the central discursive conflicts were those between air pollution as something natural versus human-made and air pollution as something serious versus not serious at all. This discursive competition was fed by a number of supporting events which were foregrounded in the media, most importantly a new report by Public Health England putting forward the number of 28,869 premature deaths per year due to air pollution in the UK (The Guardian, 11 April 2014). This number hit the headlines just after the media storm on the assumed Sahara dust started to die down and helped stir indignation about the seriousness of the crisis once more.

The peak of April 2014 set in motion a self-reinforcing spiral of public interest and media coverage: because of the higher public awareness, new information and events were taken up more quickly and more broadly in the media, and in their turn further enhanced public interest. Furthermore, media professionals seemed to search actively for newsworthy items on air pollution instead of working merely on the basis of press releases. On the $23-24^{\text {th }}$ of June 2014 a journalist from the Sunday Times attended the annual London Air Quality Conference covering one of the presentations in a by now legendary newspaper article: 'Oxford Street worst in the world for diesel pollution' (The Sunday Times, 6 July 2014). The news was quickly taken over by other news agencies but in the process some nuance got lost. 'Oxford Street is the most polluted street in the world, say scientists' headed The Independent on the $7^{\text {th }}$ of July. For the second time in a row, air pollution triggered an enormous media debate. Importantly, this deflection in translation cannot fully explain the media storm. Crucially, a similar dynamic unfolded as with the 'Saharan dust' smog alert. Instead of recognising the problem, then London mayor Boris Johnson dismissed the problem claiming that in no way Oxford Street could be the most polluted street of the world, and even threatened to withdraw the scientists' funding. In a well-shared twitter message, Johnson argued that the statement was a 'ludicrous urban myth' and that London's air was 'better than Paris and other European cities' (The Independent, 18 July 2014). 
As with the Saharan dust storm, it was this conflictual dynamic which was instrumental in pushing the topic high up the public agenda. The observation that two authorities - science and the government came to stand in opposition to each other poured oil on the fire. The public discourse became one of concerned citizens, supported by science, versus an ignorant and uninterested government. In Mouffe's $(2002,2006)$ terminology, we observed the discursive construction of an 'us' and a 'them'. The conflict fed into earlier storylines, most importantly on the positioning of Boris Johnson in relation to the air pollution crisis, has been important as well. In the years before April 2014 several much smaller peaks were exactly constructed around this nodal point: from the attempt to 'glue' pollution to the road, and thereby opt for gimmicks instead of real solutions (The Daily Telegraph, 26 March 2013), to the burying or delaying of air pollution reports (The Guardian, 24 April 2012).

The particular place of science in the public domain played an important role as well. The Oxford Street contestation cannot be fully understood without grasping the difficulties of critically engaging with complex scientific issues: how is bad air actually measured? Which pollutants have been taken into account? The translation from 'Highest annual mean concentration and most hourly $\mathrm{NO}_{2}$ exceedances in the World?' to 'Oxford Street is the most polluted street of the world' is definitely a contentious one. ${ }^{3}$ It invites people to take a position, but also to scrutinise the evidence that underpins their viewpoints on air pollution, politics and science.

The observation that representing air pollution in divisive and conflictual terms was crucial in spiking interest and debate was confirmed by the relative downturn of the spiral of media interest after November 2014. On the 13th of November, Boris Johnson admitted the scientists' claims were correct. The Times (13 November 2014) issued the headline 'Boris backs down over high pollution on Oxford Street', whereas The Guardian (13 November 2014) opted for 'London mayor makes U-turn over Oxford Street's pollution levels'. In combination with the suing of the British government for failing to meet European air pollution limit values, the news on Johnson's defeat led to a new small spike in air pollution coverage after which public interest went down and stayed lower for a while. Again, a Mouffian reading of media discourses helps to understand what is at play: the establishment of a consensus has a demobilising effect. The conflict withers away, and this has its effects on the salience of the issue in the media and in the public debate.

It took until April 2015 before media coverage on air pollution peaked again, with a new smog episode hitting the headlines in combination with new scientific findings which both grounded and heated the debate. Interestingly, journalists successfully played last year's game. Their explicit reference to the events of April 2014 not only exemplified how important the latter had been, it also enabled the journalists to develop a similar, successful narrative another time. To that aim, the previous year's story was not merely recycled, but made even more spectacular, even though it was simultaneously broadened and nuanced. The availability of new scientific figures was crucial: 'Air pollution may cause more UK deaths than previously thought, say scientists' (2 April 2015, The Guardian). At the same time, the focus moved from mortality to morbidity and effects across the lifespan. Especially the finding that air pollution leads to a lower birth weight of babies was played out in media discourse.

\footnotetext{
${ }^{3}$ King's College London air researcher David Carslaw stated on his slide during the Annual Air Quality Conference: 'Highest annual mean concentration and most hourly NO2 exceedances in the World?' https://www.londonair.org.uk/london/asp/LAQNSeminar/pdf/June2014/David Carslaw Recent findings from comprehensive vehicle emission remote sensing measurements.pdf
} 
Importantly, the conflict line on the seriousness and nature of the crisis seemed to be 'overcome' with this smog episode. This was partly the result of yet another event which was discursively constructed as supporting the 'camp' which claimed that air pollution is serious and largely human-made: ClientEarth won a supreme court ruling against the government, which was thus forced to come up with a plan to bring air pollution within legal limits (Financial Times, 30 April 2015). As the debate on the seriousness and nature of the crisis was largely settled, new conflict lines would have to be constructed to put the topic centrally on the public agenda again.

\subsection{Critical Discourse period of July 2015 - March 2016: Heathrow and Volkswagen scandal}

From July 2015 onwards a new critical discourse period can be distinguished: not only is the period exemplified by new peaks and a generally higher media coverage from then onwards, the discourse also started to centre around new conflict lines: while smog alerts and new scientific findings on air pollution and its health effects were still feeding debate and contestation, these did no longer seem the primary focus of attention. The question increasingly became what the social, economic and political root causes of air pollution are. Heathrow set the ball rolling on the $2^{\text {nd }}$ of July 2015 when, according to the Financial Times, 'a convincing case [is made] for expansion at Heathrow'. It was not the first time that a media debate on Heathrow took place, but this time air pollution figured centrally in the discussion. The Guardian (2 July 2015) issued the headline 'Heathrow expansion risks deepening London's air pollution crisis' and The Daily Telegraph (7 July 2015) underscored that 'Heathrow's measures on noise and pollution [are] "missed in report"'. A fault line was discursively constructed between airport expansion, or more broadly economic growth, and people's health. Furthermore, the composition of the constructed 'camps' started to shift. Whereas the government had figured centrally in the previous critical discourse period, the framing increasingly became one of concerned citizens versus the profit-oriented business sector, supported by the government, or even the politicaleconomic system as a whole.

This focus became even stronger when just a few months later, in September 2015, the Volkswagen scandal hit the headlines and succeeded in attracting attention for several months on end. With Volkswagen even more than with Heathrow, the target of the anger that had started to grow in relation to air pollution got a clear, though complex face. As George Monbiot (24 September 2015) suggested in the 'comment is free' section in The Guardian: 'the enemy is maybe not so much pollution, but corruption', establishing the government and industry together as responsible for the crisis London faced.

The discursive construction of new conflict lines did not mean old fault lines completely disappeared. Newspaper articles covering new information on the seriousness of the crisis continued to foster indignation and debate. A study revealing that 'air pollution in London caused early deaths of nearly 9.500 people' (The Independent, 16 July 2015) crucially contributed to the spike of public contestation on the extension plans of Heathrow in July 2015. Similarly, new data on the effects of air pollution sparked indignation about the Volkswagen scandal: 'Who knows how many people have paid for this already, with their health or with their lives?' George Monbiot wrote in The Guardian on the $24^{\text {th }}$ of September 2015, linking Volkswagen to a new report of the UK government stating that next to the 29.000 yearly premature deaths due to PM, 23.500 deaths could be attributed to NO2. Likewise, when 
the European limit values were exceeded after only 7 days in January 2016, the first conflict line, around the very nature and seriousness of the air pollution crisis, hit the headlines again.

\subsection{Critical discourse period of April 2016 - August 2016: mayoral elections, MPs and Brexit}

The critical discourse period of April 2016 - August 2016 was characterised by a new shift in the respective conflict lines: discursive struggles started to centre around which governance level ought to deal with air pollution, opening a debate about responsibilities, dependencies and power. These conflict lines had started to emerge already during the previous critical discourse period with its focus on the social, economic and political root causes of the problem. As the Financial Times pondered on the $30^{\text {th }}$ of September 2015: 'As the repercussions of the Volkswagen diesel emissions scandal multiply, one important question stands out for Europe's governments: why did they get policies so wrong?'

Three critical discourse moments, taking place at three different governance levels, have to be distinguished in this period. On the national scale, the discursive framing of air pollution as a 'public health emergency' gained centre stage. The statement of a cross-party committee of MPs that 'The Government must act now to tackle this public health emergency' (The Independent, 27 April 2016) was widely shared across media and triggered a lot of indignation and debate. At the same time, Sadiq Khan's mayoral candidacy, putting air pollution at the centre of his electoral campaign, was a key structuring discursive event at the London scale. As the Financial Times headed on the $10^{\text {th }}$ of March 2016: 'Green issues dominate London mayoral campaign'. At the international scale, the discussion on Brexit in the run-up to the referendum on the $23^{\text {rd }}$ of June 2016 was, amongst many other things, also framed in terms of air pollution. As Hannah Fearn rhetorically asked in The Independent (23 June 2015): 'What has the EU ever done for you?' Quite a lot, actually'. Amongst others, she pointed out, 'improved air quality'. In a similar vein, other actors tried to bring the importance of EU regulations for air quality in Britain to the fore. The discursive connection of leaving or remaining in the EU to air quality is remarkable. In principle, many things can become nodal points in the Brexit debate. What is discursively included and excluded in is therefore a significant political choice.

Different governance levels were portrayed as responsible for taking action, and a discursive power struggle started to emerge on who had to act first and carried most responsibility, as is typical in the game of multilevel governance (Heinelt et al., 2002; see also Kenis, 2019b). Most notable in this context was the decision of 'Sadiq Khan [to join ClientEarth in its] air pollution court case against UK government' (The Guardian, 26 May 2016). By doing that, Khan did not only profile himself as a proponent in the air pollution struggle, but also discursively moved the final responsibility to the national level. Again, the shifts of the conflict lines were supported by news coverage of smog alerts, increasing scientific evidence on the detrimental effects of air pollution (e.g. on stillbirths) and the further unfolding of previously launched storylines (e.g. Heathrow, Volkswagen, ...). At the same time, previous conflict lines became increasingly reframed in terms of the newly emerging fault lines. Examples include Sadiq Khan's pledge to pedestrianise Oxford Street and Boris Johnson's plea to leave the EU, which made critics sceptically wonder whether European air pollution 'fines [might have] fuelled the current heightening of Mr Johnson's hostility towards the EU'? (The Guardian, 23 February 2016).

On the $5^{\text {th }}$ of May 2016 Sadiq Khan was elected Mayor of London, which was discursively played out as a triumph for the air pollution struggle. However, on the $23^{\text {rd }}$ of June Brexit was a fact, which was portrayed as a defeat for air quality in the media. While some media stressed how Khan still tried to 
save the furniture by making a plea for 'stronger legal protections to make sure the existing EU limits were not undone by Brexit' (The Daily Telegraph, 6 July 2016), the case seemed settled. After Brexit the media interest in air pollution took a dip. Of course, this will not only have been due to the failure to make air pollution into a significant reason to remain in the European Union. Most importantly, in the wake of Brexit, other topics started to dominate the public and media debate.

\subsection{Critical discourse period of September 2016 - March 2017: different groups, different visions}

It took until September 2016 before air pollution hit the headlines again. The media attention for the London City Airport action of Black Lives Matter was crucial here. 'Outrage from thousands of wouldbe passengers at London City airport' headed The Guardian on the $7^{\text {th }}$ of September 2016. Without much doubt, blocking the airport can trigger a lot of heated conflict and debate. However, most importantly, the activists launched a new nodal point in the debate. By claiming that 'black people are the first to die, not the first to fly' they showed that 'air is a race issue'. The discursive focus of the debate started to shift to social divisions.

Again, new scientific studies were crucial in giving legitimacy to these claims. Just weeks after the action, a new report showed that 'London's black communities [were indeed] disproportionately exposed to air pollution' (The Guardian,10 October 2016). The observation that discriminated social groups are more affected by air pollution and in specific ways was not entirely new. Johnson had been accused earlier of burying studies which linked air pollution to deprived schools However, what was new was the framing of air pollution as a race issue beyond deprivation. The discourse increasingly centred around the observation that not all people are affected in the same way, putting environmental justice centrally in the debate. As John Vidal wrote in his opinion on the $7^{\text {th }}$ of September in The Guardian: 'The only certain things these days in the environment is that racism thrives and that pollution follows the poor'.

In line with these evolutions, the conflict lines became increasingly complex and nuanced. Air pollution was no longer 'simply' about concerned citizens against an ignorant government or profit-seeking economic sector. Suddenly, everyone seemed differently inscribed in the maps of bad air. The difficulty that arose from bringing together multiple nodal points and conflict lines was symbolised by the accusation in the media that the Black Lives Matter activists who blocked the airport were actually white ('Prominent black rights activists accused the Black Lives Matter movement in the UK of "cultural appropriation" as it emerged all nine protesters on the runway were white', The Guardian, 6 September 2016), while those involved argued that they precisely aimed at using their white privilege to put a topic on the agenda through a type of action that would have been more difficult for black people to engage in. ${ }^{4}$

On other terrains as well, this period is characterised by more nuance and complexity in the media debate. Where previously the discourse centred around 'doing something' to tackle air pollution, in autumn 2016 the focus shifted towards multiple conflicts on which measures to put in place. From 'Free public transport in London is the only way to save our environment' (The Independent, 12 December 2016) to 'Drivers of toxic diesels must pay to enter cities' (The Times, 3 November 2016)

\footnotetext{
${ }^{4}$ Without any doubt, the rise of this nodal point is also related to broader socio-political tendencies, most importantly the coming up of identity politics as a central issue in the public and media debate.
} 
and 'Driverless electric cars could cut air pollution to almost zero'(The Independent, 27 December 2016), a wide range of actors started to intervene in the media debate, trying to frame the solutions for the 'air pollution crisis' in particular directions. Previous conflict lines were partly reinvoked in this context and started to feed into the discussion, rendering the debate even more complex and multilayered. Especially when these conflict lines began to merge or clash with each other, a dynamic of public passion and indignation resulted. To give an example: on the 25th of October 2016, the governmental approval for Heathrow's expansion was widely covered in the media, while, not much later, on the 2nd of November 2016, ClientEarth's victory against the government in High Court gained a lot of media attention as well. Both media stories pointed in opposite directions, which triggered a spike in media interest and debate. In January 2017, a new smog alert was issued and broadcasted in the media. However, importantly, this time the smog alert was issued by the Mayor himself. Whereas previously scientists and citizens had to put the problem on the agenda and were often counteracted by the mayoral administration, the challenge for citizens was no longer to put the problem on the agenda, but to urge for action to be taken and to scrutinise the measures put forward. At the same time, the single news items that had been prevalent ten years earlier still appeared in the media, but in much higher numbers.

As a result of these evolutions, this period is situated high up the curve of an apparently self-reinforcing iterative cyclic process of media coverage. Once attention is high, no particular interventions are needed anymore to put the topic on the agenda. The topic seems to be on the agenda all by itself. However, our analysis also shows that obtaining a lot of media interest might not only be a positive thing. It can also create pressure to come up with always more, and by preference also more sensational or controversial, newsworthy stories, leading to a situation in which scientific findings or other stories which are not double-checked or ready for public dissemination yet, are taken up and spread. The problem is not only that, as a result, false information can start living a life of its own, spectacular figures and stories can, next to feelings of indignation, also induce unproductive levels of fear. This led to the paradoxical situation whereby atmospheric scientists started to wonder whether there was not too much attention for air pollution in the social sphere. Whereas passion is considered crucial for democratic politics (Mouffe, 2002), fear is seen as detrimental. Both Swyngedouw (2010a, 2010b) and Žižek (2008) echo Badiou's (2008) statement that ecology is 'the new opium for the masses' in this context, warning that fear can foster a situation in which democratic debate is circumvented because of the discursive staging of an urgent threat. The growing call for quick (techno)fixes, and the rise of newspaper articles on gimmicks, are significant in this regard.

\section{Concluding discussion: passion and politics}

In 'Passion and Politics: The Stakes of Democracy', Mouffe (2002) argues that it is conflict and the creation of opposing camps that stimulate people to take a position, to choose sides, to engage in debate and to form an opinion of their own. In other words, conflict has a mobilising effect: it triggers a dynamic of raising public awareness, interest and involvement. It makes a topic is taken up in the pubs and at the school gate. Importantly, to be salient, conflicts need a clear division between 'us' and 'them'. As Swyngedouw $(2007 ; 2010)$ has shown, it is exactly the lack of a clear ' $u s$ ' and 'them', or the lack of a privileged subject of change and an enemy that is internal to the social (think about $\mathrm{CO}_{2}, \mathrm{PM}$ or $\mathrm{NO}_{2}$ ) which makes many environmental issues so liable for depoliticisation (see also Kenis and Lievens, 2014). Our analysis shows that we can understand the media 'ecosystem', in particular the staging of a particular topic in the media, in a similar vein. Controversies, conflict and contestation, by 
preference articulated around clearly distinguished social camps, lead to an upward spiral of media coverage. The result is a cyclic iterative process with thresholds and critical moments, a non-linear process with a gradually increasing general level of interest and spikes during specific conjunctures. Once a certain level of interest and debate is reached, the topic starts to lead a life of its own. 'Suddenly' a range of policy reports, academic papers and civil society initiatives seemingly appears out of nowhere. Through public and mediatised conflicts 'facts' or 'events' gain a stake. Furthermore, the production of new scientific and other evidence is triggered: the conflictual dynamic makes such evidence more salient than before. It is our contention that the diachronic model of circuits of culture of Carvalho and Burgess (2005) should therefore not only be understood as a cyclic process, but, under particular circumstances, can also turn into a spiral dynamic. When media consumers become media producers, an upward spiral of citizen interest, public involvement and media coverage can take place. Different conflict lines emerge, become established and are put aside again. The debate moves on to more profound and more sophisticated discussions while previous debates come back in new shapes and become part of a complex play of interacting conflict lines.

Throughout the cyclic iterative process presented in this article we have been able to distinguish four levels of debate and related conflict lines which can - to a certain extent - be mapped onto Robert Jensen's (2002) model of different levels of knowledge and awareness formation in environmental education which we also used in previous work (Kenis and Mathijs, 2012; 2014). The first conflict line deals with the question of the nature and seriousness of the topic: is there actually a serious problem? Is the problem natural or human-made? These two questions were central in the Saharan Dust and Oxford Street debate. The second conflict line centres around the question of the social, economic and political root causes. If air pollution is human-made, who is responsible for the problem? This conflict line became very prominent in the Heathrow discussion and Volkswagen scandal. The third conflict line deals with the question of strategies for change, more specifically on which governance level or scale the problem has to be addressed. The fourth conflict line deals with future alternatives. Which are the nodal points around which alternative hegemonies can be woven? The choice for a diesel scrappage scheme, Ultra Low Emission Zone or a car-free city has roots in entirely different future imaginaries.

Importantly, an upward spiral can also come to an end. A level of saturation can be reached in which 'everything has been said'. No new media stories are constructed beyond what is already available. Other forms of saturation include the overcoming of particular conflict lines and the 'capitulation' of one of the camps. Furthermore, the conflict lines and related positions can become so stabilised that they stop moving. The situation seems stuck. As a result, the stakes go down, which will reduce the passion involved and lead to a downward spiral of interest and mobilisation. Alternatively, new issues can emerge which take the foreground. The discursive dynamic of a particular topic can never be understood in isolation. Other issues have their dynamics too. There is not only discursive competition between different storylines within the air pollution debate, but also between different topics competing for a place on the public agenda and in the media debate. How interesting is a new report on the health effects of air pollution if a terrorist attack takes place the same day? To paraphrase Jonathan Freedland in The Guardian on the $18^{\text {th }}$ of January 2019, what are the things which 'we don't talk about when we only talk about Brexit'? 


\section{References}

Adey P (2013) Air/Atmospheres of the Megacity. Theory, Culture \& Society 30: 291-308.

Antilla L (2005) Climate of scepticism: US newspaper coverage of the science of climate change. Global Environmental Change 15: 338-352.

Baxter J and Eyles J (1997) Evaluating Qualitative Research in Social Geography: Establishing 'Rigour' in Interview Analysis. Transactions of the Institute of British Geographers 22: 505-525.

Bickerstaff $\mathrm{K}$ and Walker $\mathrm{G}$ (2001) Public understandings of air pollution: the 'localisation' of environmental risk. Global Environmental Change 11: 133-145.

Boykoff M (2008) Lost in translation? United States television news coverage of anthropogenic climate change, 1995-2004. Climatic Change 86: 1-11.

Carvalho A (2007) Ideological cultures and media discourses on scientific knowledge: re-reading news on climate change. Public understanding of science 16: 223-243.

Carvalho A (2008) Media (ted) discourse and society: Rethinking the framework of critical discourse analysis. Journalism studies 9 9: 161-177.

Carvalho A (2010) Media (ted) discourses and climate change: a focus on political subjectivity and (dis) engagement. Wiley Interdisciplinary Reviews: Climate Change 1: 172-179.

Carvalho A and Burgess J (2005) Cultural circuits of climate change in UK broadsheet newspapers, 1985-2003. Risk Analysis: An International Journal 25: 1457-1469.

Craig G (2010) Dialogue and dissemination in news media interviews. Journalism 11: 75-90.

Cupples J (2009) Culture, nature and particulate matter - Hybrid reframings in air pollution scholarship. Atmospheric Environment Volume 43: 207-217.

Cupples J, Guyatt V and Pearce J (2007) "Put on a Jacket, You Wuss": Cultural Identities, Home Heating, and Air Pollution in Christchurch, New Zealand. Environment and Planning A: Economy and Space 39: 2883-2898.

Day R (2007) Place and the experience of air quality. Health \& Place 13: 249-260.

Dispensa JM and Brulle R (2003) Media's social construction of environmental issues: Focus on global warming - A comparative study. International Journal of Sociology and Social Policy 23: 74105.

Engelmann S (2015) Toward a poetics of air: sequencing and surfacing breath. Transactions of the Institute of British Geographers 40: 430-444.

Fairclough N (1995) Critical Discourse Analysis. Boston: Addison-Wesley

Heinelt H, Getimis P, Kafkalas G, et al. (2002) Participatory Governance in Multi-Level Context: Concepts and Experience. Wiesbaden: Springer.

Hoffman J (2004) Citizenship Beyond the State. London: SAGE Publications.

Howarth D (2000) Discourse. Buckingham: Open University Press.

Howarth D, Norval AJ and Stavrakakis Y (2000) Discourse theory and political analysis. Identities, hegemonies and social change. Manchester: University Press.

Jensen BB (2002) Knowledge, Action and Pro-environmental Behaviour. Environmental Education Research 8: 325-334.

Kay S, Zhao B and Sui D (2015) Can Social Media Clear the Air? A Case Study of the Air Pollution Problem in Chinese Cities. The Professional Geographer 67: 351-363.

Kenis A (2015) From Individual to Collective Change and Beyond. Ecological Citizenship and Politicisation. Phd Dissertation.

Kenis A (2019a) Post-Politics Contested: Why Multiple Voices on Climate Change do not equal Politicisation. Environment and Planning C: Politics and Space 37(5): 831-848.

Kenis A (2019b) Air Pollution in times of Brexit: Civil Society and the Contested Game of Multilevel Governance. Presented at the Resistance is in the Air: Citizens, science and air pollution. International interdisciplinary symposium, Brussels, 25-27 Apr 2019.

Kenis A (2020) Science, Citizens and Air Pollution: Constructing Environmental (In)Justice. In: Davies T and Mah A (eds) Environmental justice and citizen science in a post truth age. Manchester: Manchester University Press. 
Kenis A and Lievens M (2014) Searching for 'the political' in environmental politics. Environmental Politics 23(4): 531-548.

Kenis $A$ and Lievens $M$ (forthcoming) Politicizing air: on the political effects of spatial imagination. In: Landau F, Pohl L Roskam N (Eds) [Un]Grounding: Post-foundational geographies. London: Transcript.

Kenis A and Mathijs E (2012) Beyond Individual Behaviour Change: The Role of Power, Knowledge and Strategy in Tackling Climate Change. Environmental Education Research 18(1): 45-65.

Kenis A and Mathijs E (2014) Climate Change and Post-Politics: Repoliticising the Present by Imagining the Future? Geoforum 52: 148-156.

Laclau E and Mouffe C (2001) Hegemony and Socialist Strategy : towards a Radical Democratic Politics. London: Verso.

Latour B (2004) Why Has Critique Run out of Steam? From Matters of Fact to Matters of Concern. Critical Inquiry 30: 225-248.

Maeseele P (2015) Risk conflicts, critical discourse analysis and media discourses on GM crops and food. Journalism 6: $278-297$.

Maeseele P and Raeijmaekers D (2017) Nothing on the news but the establishment blues? Toward a framework of depoliticization and agonistic media pluralism. Journalism https://doi.org/10.1177/1464884917739476.

Mayer B (2012) 'Relax and take a deep breath': Print media coverage of asthma and air pollution in the United States. Social Science \& Medicine 75: 892-900.

Mitchell G and Dorling D (2003) An environmental justice analysis of British air quality. Environment and Planning $A$ 35: 909-929.

Mouffe C (2002) Politics and passions. The stakes of democracy. London: CSD Perspectives.

Mouffe C (2006) On the political. London: Routledge.

Moyer A, Greener S, Beauvais J, et al. (1995) Accuracy of health research reported in the popular press. Health Communication 7: 147-161.

Olausson U (2010) Towards a European identity? The news media and the case of climate change. European Journal of Communication 25: 138-152.

Pearce JR, Richardson EA, Mitchell RJ, et al. (2011) Environmental justice and health: a study of multiple environmental deprivation and geographical inequalities in health in New Zealand. Social Science \& Medicine 73: 410-420.

Pepermans Y (2015) The manufacturing of climate consent from a depoliticized consensus to politicized debate. Faculteit Politieke en Sociale Wetenschappen, Departement Communicatiewetenschappen. Antwerpen: UA.

Pepermans Y and Maeseele P (2014) Democratic Debate and Mediated Discourses on Climate Change: From Consensus to De/politicization. Environmental Communication 8: 216-232.

Rear D (2013) Laclau and Mouffe's Discourse Theory and Fairclough's Critical Discourse Analysis:

An Introduction and Comparison. Unpublished research paper. Available online: academia.edu

Seale C (2003) Media and Health. London: SAGE Publications.

Swyngedouw E (2007) Impossible "Sustainability" and the Postpolitical Condition. In: Krueger R and Gibbs D (eds) The Sustainable Development Paradox. London: The Guilford Press.

Swyngedouw E (2010) Apocalypse Forever? Theory, Culture \& Society 27: 213-232.

van Dijk T (1988). News as Discourse. Hillsdale: Laurence Erlbaum.

Wakefield SEL, Elliott SJ, Cole DC, et al (2001) Environmental risk and (re)action: air quality, health, and civic involvement in an urban industrial neighbourhood. Health \& Place 7: 163-177.

Wodak, R (1999) Critical Discourse Analysis at the End of the 20th Century, Research on Language and Social Interaction 32(1-2): 185-193. 